\title{
The economic consequences of the coronavirus pandemic: which groups will suffer more in terms of loss of employment and income?
}

\author{
Marina A. Kartseva, Polina O. Kuznetsova ${ }^{1}$ \\ 1 RANEPA, Moscow, 119034, Russia
}

Received 4 April 2020 • Accepted 13 April 2020 • Published 22 April 2020

Citation: Kartseva MA, Kuznetsova PO (2020) The economic consequences of the coronavirus pandemic: which groups will suffer more in terms of loss of employment and income? Population and Economics 4(2): 26-33. https:// doi.org/10.3897/popecon.4.e53194

\begin{abstract}
The paper estimates the scale of the possible impact of the coronavirus epidemic on the Russian labor market and household incomes. We consider vulnerable employment, which includes workers with increased risks of job loss, wage cuts and other negative events that reduce labor incomes.

The analysis shows that every second Russian worker can be classified as vulnerable employee. The highest risks for reducing labor incomes as a result of the epidemic are faced by young people, workers with a low level of education, as well as residents of regional centers. About a third of vulnerable employees experience complex vulnerability, i.e. meet several criteria of vulnerability.

A decrease in labor incomes could also affect the wealth of about $40 \%$ of Russian households. The worst situation is for younger families, whose incomes are much more dependent on the labor market. Most of the households in which vulnerable workers live do not receive social benefits, and therefore it would be rather difficult for them to count on prompt assistance from the social protection system.

Currently Russia is actively developing a set of measures to support employment. In particular, government decided to provide support for the most affected by COVID sectors, the size of unemployment benefits has been increased for citizens who have lost their jobs due to the epidemic. However, it is obvious that this list should be extended and account for various forms of deterioration of employment.
\end{abstract}

\section{Keywords}

COVID-19, lockdown, vulnerable employment, household income, Russia

JEL codes: E24, I31

Copyright Kartseva MA, Kuznetsova PO. This is an open access article distributed under the terms of the Creative Commons Attribution License (CC-BY 4.0), which permits unrestricted use, distribution, and reproduction in any medium, provided the original author and source are credited 


\section{Introduction}

The coronavirus pandemic noticeably manifested itself in Russia - two months later than in China, and with an about two-week lag behind the countries of Western Europe, among which Italy and Spain were most seriously affected at the beginning of April (CSSE, 2020). About the same time as in Russia, that is, in mid-March, the pandemic began to unfold in the United States, which by the beginning of April were already noticeably ahead of other countries in the number of recorded cases. In Russia, partly for objective reasons (lower passenger traffic with the countries that were affected by the pandemic first), partly due to the relatively rapid introduction of restrictive measures, the number of diseases did not grow as fast. However, the average doubling of the number of cases in March 2020 occurred in 3-4 days.

However, the situation in Russia is also alarming, as can be seen from morbidity and mortality data (CSSE, 2020). There are signs of an active phase of the pandemic, including an increase in the number of new cases and the spread of the disease across the country (as of 4 April, the virus was detected in 78 regions). In order to combat the pandemic, Russia, following other countries, has imposed significant restrictions on the movement of citizens. Among these restrictive measures, the transfer of the majority of workers on paid leave is particularly noticeable. For the first time, a non-working week was announced from $30 \mathrm{March}$, then the forced leave was extended until the end of April. Similar holidays for adults were previously introduced in China, Italy, Spain, France and other countries (Maleva et al. 2020).

The coronavirus pandemic is a major shock to the Russian labor market. Temporary closure of enterprises and organizations, with the exception of those responsible for life support and emergency services, prolonged strict lockdown for citizens, restrictions for air and railway travel in the context of a decline in aggregate demand will inevitably have a negative impact on Russian business. The volume of production of a significant part of enterprises will decrease, some enterprises will go bankrupt. Such a situation may lead to mass dismissals of employees, a significant decrease in wages, delays in payments, forced leave. The self-employed and individual entrepreneurs, workers of the industries most affected by the coronavirus, and workers whose employment was precarious before the pandemic are most vulnerable to loss of labor income.

In such circumstances, an assessment of the possible economic effect of quarantine on the population of the country with the help of representative household surveys is relevant. In this paper an attempt is made to assess the scale of the possible effect of the pandemic on the population welfare. We use the concept of vulnerable employment for this purpose. Vulnerable employment refers to increased risk of dismissal, reduction of wages, reduction of working hours and other negative events that may reduce employees' incomes. In the paper the prevalence of vulnerable employment among workers of various socio-demographic groups, as well as among households are analyzed.

\section{Vulnerability of employment}

In order to assess the scale of the possible negative effect of the coronavirus pandemic on the welfare of citizens, the paper formulated a definition of vulnerability of employment. Vulnerable workers have increased risks of deterioration of their working status (dismissal, reduction of wages, reduction of working hours, etc.). In the context of the coronavirus pandemic, the following groups are considered vulnerable: 
1. Self-employed and individual entrepreneurs.

2. Workers in the sectors most affected by the pandemic, namely transport, culture, leisure and entertainment, physical culture and sports, tourism and hospitality, catering, household services and education, those employed in non-government enterprises and non-government organizations (the list of industries was identified by Russian government - URL: https://www.rbc.ru/business/30/03/2020/5e819d039a7947925edc003a).

3. Employed workers with precarious employment. Precarious employment means unreliability, instability in labor relations and is characterized by a low degree of worker protection. The phenomenon of instability of employment is well studied in the Russian scientific literature. In this study, the choice of criteria of instability is based on studies (Bobkov 2017; Bobkov et al. 2017; Unsustainable employment in the Russian Federation 2018). We believe that the employment of an employee is unstable if it has one of the following characteristics:

- low wages (wages that are lower than the subsistence level of the working age population established in the region);

- informal wages;

- absence of a formal contract;

- delays in payment of wages (in the last 12 months);

- reduction of wages, involuntary reduction of working hours (in the last 12 months);

- forced unpaid leave (in the last 12 months).

In this study, an employee is considered vulnerable to the pandemic if he belongs to at least one of the three groups listed (self-employed, employed in the most affected industries and precarious workers

The empirical basis of the study is microdata of the 27th wave of the Russia Longitudinal Monitoring Survey - Higher School of Economics, conducted in 2018 (see RLMS-HSE web sites: http://www.cpc.unc.edu/projects/rlms-hse, http://www.hse.ru/org/hse/rlms).

\section{Results}

\section{Prevalence of employment vulnerability among workers of various socio-demographic types}

Analysis has shown that the employment of every second Russian worker is vulnerable to the coronavirus pandemic. In other words, half of those employed in the Russian labor market are currently experiencing high risks of dismissal, reduction of wages, delays in payments, forced leave, etc. Therefore, for these workers, the risk of total loss or substantial reduction of their employment income should be assessed as serious.

The vulnerability of workers to the pandemic varies considerably among socio-demographic groups (see table 1). The maximum risk of deterioration of the employment status is observed among young workers (under 30 years of age) - among them the share of those vulnerable is $57 \%$. With age, the risk of income decline due to pandemic somewhat decreases. Most sustainable and stable is the employment of persons between the ages of 50 and 59. For this group of workers, the prevalence of employment vulnerability is $43 \%$. Interestingly, there is no gender variation in the vulnerability of employed.

Employed living in regional centers seem to be more vulnerable than those living in other cities and rural areas. In regional centers over half (54\%) of workers experience a high risk of job loss or deterioration of employment characteristics, while among employed residents of other cities and rural areas, $48 \%$ and $45 \%$ respectively are vulnerable. 
Table 1. Vulnerability among various socio-demographic groups of workers, Russia, 2018.

\begin{tabular}{|c|c|c|}
\hline Group of workers & $\begin{array}{c}\text { Percentage of vulnerable } \\
\text { employees, } \%\end{array}$ & $\begin{array}{c}\text { Share of employed, \% } \\
\text { (reference) }\end{array}$ \\
\hline All employees & $49.7 \%$ & $100 \%$ \\
\hline \multicolumn{3}{|l|}{ Gender } \\
\hline Men & $49.5 \%$ & $49.4 \%$ \\
\hline Women & $49.9 \%$ & $50.6 \%$ \\
\hline \multicolumn{3}{|l|}{ Age } \\
\hline Under 30 years & $56.8 \%$ & $22.4 \%$ \\
\hline $30-39$ & $50.3 \%$ & $25.7 \%$ \\
\hline $40-49$ & $48.9 \%$ & $25.5 \%$ \\
\hline $50-59$ & $42.5 \%$ & $20.7 \%$ \\
\hline 60 years and older & $48.1 \%$ & $5.8 \%$ \\
\hline \multicolumn{3}{|l|}{ Type of settlement } \\
\hline Regional center & $54.4 \%$ & $43.1 \%$ \\
\hline Other city (not the district center) & $47.6 \%$ & $29.9 \%$ \\
\hline Rural area & $44.5 \%$ & $27.0 \%$ \\
\hline \multicolumn{3}{|l|}{ Education } \\
\hline Not higher than general secondary & $64.6 \%$ & $13.7 \%$ \\
\hline Primary professional & $55.9 \%$ & $27.0 \%$ \\
\hline Secondary professional & $48.6 \%$ & $25.2 \%$ \\
\hline Higher professional & $39.5 \%$ & $34.2 \%$ \\
\hline
\end{tabular}

Source: Estimation based on RLMS HSE data, 2018

Among educational groups, workers with a low level of education (general secondary and lower) are the most vulnerable. Among this category of employed, almost two thirds (65\%) of citizens face a high risk of loss or deterioration of employment conditions. Professional education increases the stability and sustainability of employment in the harsh conditions of the pandemic. Among workers with primary professional education, 56\% are vulnerable. Among those employed with secondary professional education, the same parameter is $49 \%$. The coronavirus pandemic poses the least threat to the employment of persons with higher education, although the risks of deterioration in the labor market are high $-40 \%$ of workers with higher professional qualifications education are currently in a vulnerable situation.

We can consider the main sources of vulnerability of workers. The largest group of workers with a high risk of loss or deterioration of employment characteristics are those working in the most affected industries - 63\% (see Figure 1). Also, over half the vulnerable workers (51\%) have precarious employment. One in five vulnerable workers is self-employed. Two thirds of the vulnerable laborers experience only one type of vulnerability. However, the vulnerability of employment for the remaining third is complex $-34 \%$ of vulnerable laborers are vulnerable according to two criteria, which certainly increases the risk of deterioration of their position in the labor market. 


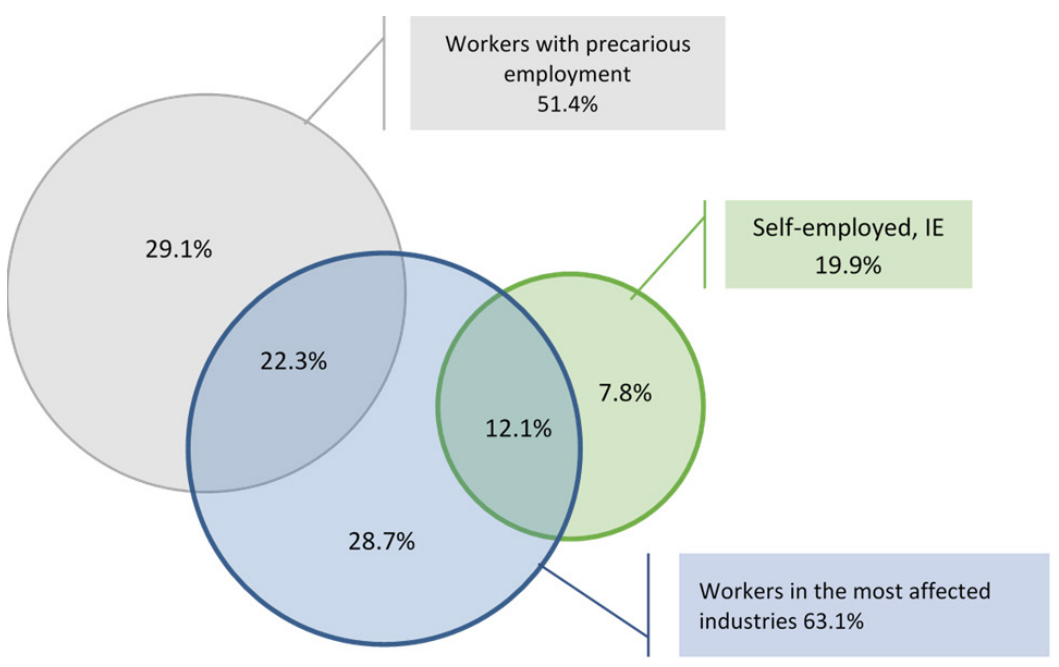

Figure 1. Structure of workers vulnerable to the coronavirus pandemic by source of vulnerability, \%. Source: Estimation based on RLMS HSE data, 2018

\section{Prevalence of risk of a sharp decline in income due to the coronavirus pandemic among households}

Labor income is the most important component of the family budget. As a result, the risks of falling labor income due to the coronavirus pandemic also affect expected household income. In order to find out which types of households are most likely to be affected by lockdown, we have considered two definitions of households that are likely to encounter a marked decline in income in the near future. First, these are households with at least one worker who we previously identified as vulnerable to the consequences of the pandemic, and secondly, households where all employed are vulnerable. From now on, such households will be called vulnerable.

Estimates show that $39 \%$ of households with high risk of income loss due to lockdown and other consequences of the pandemic (Table 2). Despite some smoothing of losses at the household level compared to the individual (let us recall, the share of vulnerable employment according to our calculations is $50 \%$ ), it is nevertheless rather significant. Moreover, in almost a quarter of Russian households (24\%) all workers are engaged in vulnerable employment, which makes the financial situation of these families even less stable.

A comparison of the risk of loss of labor income by household group leads to the conclusion that families with children are in the worst situation (about $60 \%$ of vulnerable households) as well as households without children and pensioners (51\%), that is, younger households in general, whose incomes are much more dependent on the labor market. The presence of pensioners in the household, i.e. recipients of stable non-employment income, significantly reduces the risk of a sharp decline in income as a result of the pandemic ( $26 \%$ of vulnerable persons).

As in the case of individual employment, the risks of income decline from the pandemic are higher in regional centers and other cities (42\% and $40 \%$ ) than in rural areas (34\%), which perhaps is due to the higher incidence of urban employment in the services sector, most affected by the restrictions imposed by the pandemic control. 
Table 2. Households with vulnerable employed

\begin{tabular}{|c|c|c|c|}
\hline Type of household & $\begin{array}{c}\text { Percentage of } \\
\text { households with at } \\
\text { least one vulnerable } \\
\text { worker, } \%\end{array}$ & $\begin{array}{c}\text { Percentage of } \\
\text { households in } \\
\text { which all workers } \\
\text { are engaged } \\
\text { in vulnerable } \\
\text { employment,\% }\end{array}$ & $\begin{array}{c}\text { Share of all } \\
\text { households,\% } \\
\text { (reference) }\end{array}$ \\
\hline All households & 38.9 & 23.9 & 100 \\
\hline \multicolumn{4}{|l|}{$\begin{array}{l}\text { By number of children under } 18 \\
\text { years of age }\end{array}$} \\
\hline $\begin{array}{l}\text { No children } \\
\text { of which }\end{array}$ & \multicolumn{2}{|c|}{ of which } & 69.2 \\
\hline without children and pensioners & 51.4 & 31.7 & 19.2 \\
\hline \multicolumn{4}{|l|}{ of which } \\
\hline with 1 child & 58.1 & 31.1 & 17.8 \\
\hline with 2 children & 60 & 31.3 & 9.9 \\
\hline with 3 or more children & 58.8 & 31.7 & 3.1 \\
\hline \multicolumn{4}{|l|}{ By place of residence } \\
\hline Regional Center & 41.8 & 26.4 & 42.5 \\
\hline Other cities & 39.9 & 23.2 & 26.6 \\
\hline Rural area & 33.9 & 20.9 & 30.9 \\
\hline \multicolumn{4}{|l|}{ Other categories of households } \\
\hline Living alone & 14.1 & 14.1 & 25.7 \\
\hline Of which at working age & 36.3 & 36.3 & 6 \\
\hline $\begin{array}{r}\text { Households receiving social } \\
\text { assistance }\end{array}$ & 27 & 17.9 & 32 \\
\hline $\begin{array}{r}\text { Households not receiving } \\
\text { social assistance }\end{array}$ & 44.4 & 26.7 & 68 \\
\hline Households with pensioners & 26.4 & 17.6 & 59.2 \\
\hline
\end{tabular}

Source: Estimation based on RLMS HSE data, 2018

It is particularly noteworthy that most households with a high risk of income decline do not receive social benefits. Accordingly, these households are not currently integrated into the State social protection system and there is doubt that, in the event of a sharp fall in income, their consumption level will be cushioned by the timely provision of social assistance.

\section{Conclusions}

The coronavirus pandemic represents a significant challenge for the Russian labor market. Currently, when the pandemic in Russia is just unfolding and the business and population support package is under development, it is difficult to accurately assess to what extent the pandemic will affect various aspects of employment. However, there is no doubt that the 
scale of the impact is unprecedented. The study has shown that one in two Russian workers faces an increased risk of dismissal or deterioration of employment characteristics. At the same time, one third of the vulnerable workers experience complex vulnerability, which significantly worsens their position in today's labor market. In terms of socio-demographic characteristics, young people, workers with low levels of education and regional centers residents face the greatest risks of income reduction as a result of the pandemic.

Risks of falling income from employment also affect expected household income - the share of households with a high risk of income loss due to lockdown and other consequences of the pandemic is, according to our calculations, 39\%. Families with children (about $60 \%$ of vulnerable households) and households without children and pensioners (51\%), that is, younger households whose incomes are much more dependent on the labor market, face the worst situation. The majority of households with vulnerable workers do not receive social benefits, making it difficult for them to rely on prompt assistance from the system of social protection.

The Russian situation is not unique. The labor markets of all countries affected by the coronavirus, without exception, are experiencing a similar shock. Many countries have introduced measures to support citizens whose labor market situation has deteriorated significantly as a result of the pandemic. Among the measures used are relaxing the eligibility criteria for obtaining unemployment benefit, the possibility of receiving unemployment benefits not only on dismissal but also on a substantial reduction in wages, increase in the period and amount of payments, assistance in employment, assistance in improving skills. It is also an important step by the governments of a number of countries to support businesses that encourage the retention of workers. These measures include subsidies and discounts, deferment of mandatory payments for firms that avoided or minimized dismissal, state co-financing of employees' salaries, measures to stimulate employment in strategically important industries. A detailed overview of measures to support workers in the context of the coronavirus pandemic is presented in an analytical note (Maleva et al. 2020).

Currently, Russia is actively developing a set of measures to support employment. Thus, in particular, a decision has already been taken to support the industries most affected by the pandemic, and the unemployment benefit for citizens who have lost their jobs because of the pandemic has been increased. However, this list of measures is not final. It is already clear that such measures should be substantially broader, encompassing various forms of deterioration in the employment parameters of citizens and should be integrated. Understanding the characteristics and patterns of vulnerability will help policymakers shape both effective labor market policies and effective targeted social support measures aimed at maintenance of the welfare of Russian citizens.

\section{Reference list}

Bobkov VN (2017) Unstable employment in the formal economy of Russia - the main reason for informal employment // Living Standards of the Population of Regions of Russia. № 1 (203): 7-16. (in Russian)

Bobkov VN, Kvachev VG, Loktyukhina NV, Richcheri M (2017) Criteria, probability, and degree of instability of employment taking into account the features of the Russian labor market. Economy of region. 13(3): 672-683.

CSSE (2020) Database of The Center for System Science and Engineering (CSSE) at John Hopkins University. https:/github.com/CSSEGISandData/COVID-19/tree/master/csse_covid_19_data/ csse_covid_19_time_series. 
Maleva TM, Salmina AA, Grishina EE, Kartseva MA, Kuznetsova PO, Khasanova RR (2020) Evaluation of the effectiveness of antiepidemiological and social government measures in different regions - Northern Europe, Central Europe, Southern Europe, China, America. http://www.demoscope.ru/weekly/2020/0853/coronavirus01.php (in Russian)

Unsustainable employment in the Russian Federation: theory and methodology of identification, estimation and reduction vector: scientific monograph (2018) Joint monograph. Bobkov VN (ed.) M.: KNORUS. 342 p. (in Russian)

\section{Information about the authors:}

- Kartseva Marina Anatolyevna, Senior Researcher at the Institute for Social Analysis and Forecasting of the Russian Presidential Academy of National Economy and Public Administration.E-mail: mkartseva@mail.ru

- Kuznetsova Polina Olegovna, Senior Researcher at the Institute for Social Analysis and Forecasting of the Russian Presidential Academy of National Economy and Public Administration. E-mail: polina.kuznetsova29@gmail.com. 